\title{
Comparative Experimental Study of Tribo-Mechanical Performance of Low-Temperature PVD Based TiN Coated PRCL Systems for Diesel Engine
}

\author{
Ghulam Moeen Uddin (D), ${ }^{1}$ Muhammad Sajid Kamran, ${ }^{1}$ Jawad Ahmad (D), \\ Muhammad Ghufran (D), ${ }^{1}$ Muhammad Asim, ${ }^{1}$ Muhammad Qasim Zafar, \\ Muhammad Irfan, ${ }^{3}$ Bilal Waseem, ${ }^{3}$ Awais Ahmad Khan ${ }^{1 D},{ }^{1}$ \\ Muhammad Jawad, ${ }^{1}$ Ibrahim Zeid, ${ }^{4}$ and Sagar Kamarthi ${ }^{4}$ \\ ${ }^{1}$ Department of Mechanical Engineering, University of Engineering \& Technology, Lahore 54890, Pakistan \\ ${ }^{2}$ Department of Mechanical Engineering, Tsinghua University, Beijing 100084, China \\ ${ }^{3}$ PITMAEM, PCSIR Laboratories Complex, Lahore 54000, Pakistan \\ ${ }^{4}$ Mechanical and Industrial Engineering Department, Northeastern University, Boston, MA 02115, USA
}

Correspondence should be addressed to Ghulam Moeen Uddin; ghulammoeenuddin@uet.edu.pk

Received 3 June 2018; Accepted 17 October 2018; Published 12 December 2018

Academic Editor: Shyam Bahadur

Copyright (C) 2018 Ghulam Moeen Uddin et al. This is an open access article distributed under the Creative Commons Attribution License, which permits unrestricted use, distribution, and reproduction in any medium, provided the original work is properly cited.

\begin{abstract}
Piston ring and cylinder liner (PRCL) interface is a major contributor to the overall frictional and wear losses in an IC engine. Physical vapor deposition (PVD) based ceramic coatings on liners and rings are being investigated to address these issues. High temperature requirements for applications of conventional coating systems compromise the mechanical properties of the substrate materials. In the current study, experimental investigation of tribo-mechanical properties is conducted for various titanium nitride (TiN) coated PRCL interfaces in comparison with a commercial PRCL system. Low-temperature PVD based TiN coating is successfully achieved on the grey cast iron cylinder liner samples. Surface roughness of the grey cast iron cylinder liner substrates and the thickness of TiN coating are varied. A comprehensive comparative analysis of various PRCL interfaces is presented and all the trade-offs between various mechanical and tribological performance parameters are summarized. Coating thickness between 5 and 6 micrometres reports best tribo-mechanical behaviour. Adhesion and hardness are found to be superior for the TiN coatings deposited on cylinder liner samples with higher roughness, i.e., 5-micron Ra. Maximum 62 \% savings on the COF is reported for a particular PRCL system. Maximum 97\% saving in cylinder liner wear rate is reported for another PRCL system.
\end{abstract}

\section{Introduction}

Friction and wear in internal combustion (IC) engines, particularly on the sliding interface of the piston ring cylinder liner (PRCL) system are very critical to the fuel consumption and maintenance cost. The total losses due to all types of friction are nearly one-fourth (25\%) of the overall fuel consumption and $50 \%$ of these frictional losses are due to PRCL system interface in IC engines $[1,2]$. Therefore, reducing the coefficient of friction (COF) and wear at PRCL interface plays a vital role in fuel savings, reduction in maintenance cost, enhancement in efficiency, life, and reliability of the engine [3].
One prospective solution to friction and wear losses at PRCL interfaces is the deposition of ceramic coatings on the components of PRCL system $[4,5]$. Titanium nitride (TiN) ceramic coating is a single metal nitride ceramic material having high hardness and excellent wear resistance. It is being widely used commercially for many years in different mechanical and tribological applications [6]. Physical Vapor Deposition (PVD) process is a well-known, established, and commercially viable method of depositing TiN coatings [7]. Conventional PVD systems require $400-500^{\circ} \mathrm{C}$ deposition temperature of the substrate material during TiN coatings [8]. The cylinder liners of commercial diesel engines are generally 
TABLE 1: Description of PRCL interface systems.

\begin{tabular}{lcc}
\hline PRCL systems & No of Samples & Description \\
\hline PRCL system 1 (As is scenario) & 1 & Uncoated cylinder liner interface with Chromium (Cr) coated ring \\
PRCL system 2 & 6 & Titanium nitride (TiN) coated cylinder liner interface with TiN coated piston \\
rings
\end{tabular}

made of grey cast iron. The grey cast iron is tempered at 300$370^{\circ} \mathrm{C}$ range [9]. This range of the tempering temperature is a fundamental challenge to the application of TiN coatings at the PRCL interface of these engines because grey cast iron loses it hardness after tempering. In the present study, lowtemperature PVD (substrate temperature of $250^{\circ} \mathrm{C}$ during deposition) of the PRCL interface of a diesel engine has been demonstrated. We recorded positive results in terms of micromechanical and tribological performance of the interfacing surfaces of a commercial diesel engine PRCL system.

The surface finish of the cylinder liner is another key factor that affects the application of TiN coatings in terms of the micromechanical properties of the interfacing surfaces and tribological performance of the PRCL system [10-12]. In the current study, commercially available grey cast iron cylinder liners have been employed for experiments. These cylinder liners are honed and have a surface roughness $(\mathrm{Ra})$ of was $0.55 \pm 0.05 \mu \mathrm{m}$ for this study. It was also studied the impact of reducing the surface roughness of the cylinder liners on the micromechanical properties of the TiN coatings and the tribological performance of the PRCL system interfaces. The other important parameter that affects the micromechanical and tribological performance of TiN coatings is the thickness of the coating itself $[13,14]$. The increases in coating thickness improve the hardness, adhesion, and wear resistance of the coating [15].

This research presents a comprehensive comparison of micromechanical and tribological properties of an existing diesel engine PRCL system with various combinations of lowtemperature PVD coated interfacing surfaces of same PRCL system. In order to enhance the commercial utilization of this work, an investigation is carried out on the impact of varying the surface roughness of grey cast iron cylinder liner substrates and $\mathrm{TiN}$ coating thickness on the micromechanical and tribological performance.

\section{Experimental Work}

2.1. Sample Preparation. Four different PRCL (Piston Ring Cylinder Liner) interface system samples were prepared and tested for comparison of mechanical and tribological performance. These PRCL interface systems are described in Table 1.

Commercially available cylinder liner and piston rings of the tractor $85 \mathrm{HP}$ were collected and cut into small samples. Grey cast iron cylinder liner samples were sized to $25 \mathrm{~mm} \times 20 \mathrm{~mm}$. TiN coating was deposited on the cylinder liner samples using low-temperature Physical Vapor Deposition (PVD) process. Two parameters, surface roughness and coating thickness, were varied while preparing the cylinder liner samples. Two sets of samples were polished with emery papers (600-1500-micron grit size), in order to achieve two different surface roughness ranges, i.e., $0.2 \pm 0.05$ $\mu \mathrm{m} \mathrm{R}_{\mathrm{a}}$ (called fine samples) and $0.45 \pm 0.05 \mu \mathrm{m} \mathrm{R}_{\mathrm{a}}$ (called rough samples). The roughness of the sample surface was measured by using surface roughness tester Mitutoyo (model SJ-20). Three readings of each sample surface at the different locations were recorded and the average $R_{a}$ of the three reading was recorded as the roughness value for a particular sample. Three batches of four samples each, constituting two numbers of the rough and two numbers of fine samples each batch, were deposited with three different deposition time using a low-temperature PVD system. The piston rings of the same engine were cut in matching dimensions of the cylinder liner samples.

2.2. TiN Coating Deposition. Titanium nitride (TiN) was coated on three batches (12 samples of PRCL systems 2 and 3) of cylinder liner samples under similar deposition conditions using the low-temperature cathodic arc metal source PVD coating system. Prior to TiN deposition, the cylinder liner samples were cleaned in an ultrasonic bath with trichloroethylene at $80^{\circ} \mathrm{C}$ for 15 minutes. The samples were blow dried with pure argon gas (N5.0). After drying the samples were transported to the low-temperature PVD chamber. The chamber was evacuated up to $6 \times 10^{-6} \mathrm{mbar}$ vacuum and the temperature of the samples was increased up to $250^{\circ} \mathrm{C}$. For the PVD deposition process, highly pure nitrogen gas (N5.0) was used as the reactive gas and highly pure argon gas (N5.0) was used as the working gas. Argon and nitrogen gas was supplied through a mass flow controller at $20 \mathrm{sccm}$ and $275 \mathrm{sccm}$, respectively. The $200 \mathrm{~V}$ substrate bias voltage is applied during deposition. This process is repeated for all three batches for corresponding three different deposition times, i.e., $15 \mathrm{~min}, 30 \mathrm{~min}$, and $45 \mathrm{~min}$. One set of the chromium coated ring cut outs was also coated with the 45minute batch. Summary of cylinder liner samples of all PRCL systems along with roughness and deposition time is given in Table 2 .

2.3. Scratch Test for Coating Adhesion. In order to assess the adhesion of the TiN coatings with the grey cast iron cylinder liner substrate, a scratch test was performed. This test has been widely used for measuring the adhesion of hard coatings in the previous studies $[16,17]$. The scratch 


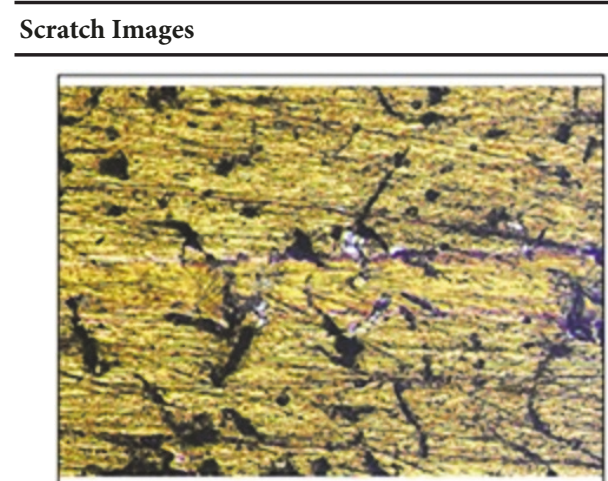

Lc1.

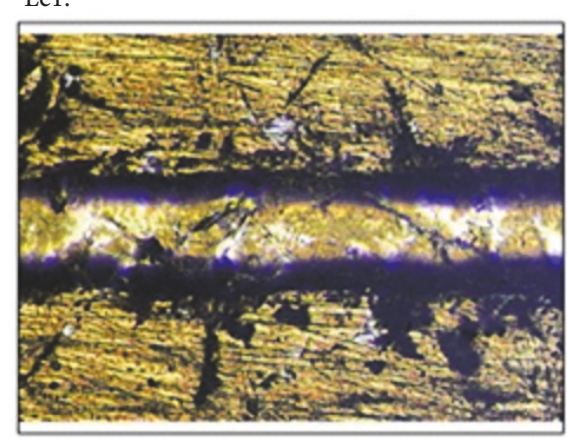

Lc3.

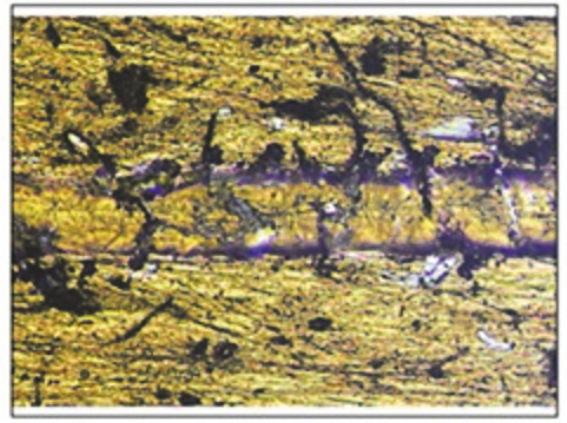

Lc2.

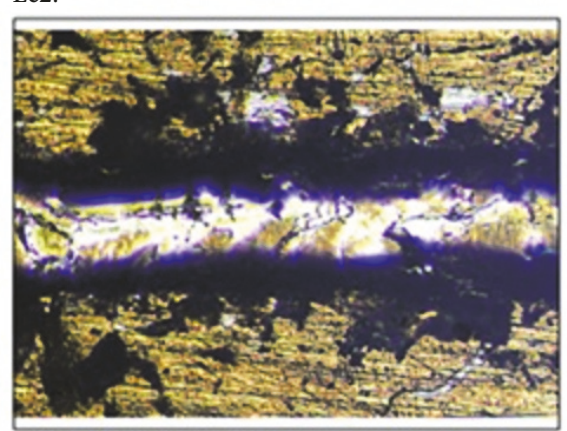

Complete Delamination.

FIgURE 1: Scratch images of intermediate thick TiN coated cylinder liner sample.

TABLE 2: Summary of cylinder liner samples of all PRCL systems along with roughness and deposition time.

\begin{tabular}{lccc}
\hline PRCL system & Sample ID & $\begin{array}{c}\text { Surface } \\
\text { Roughness }\end{array}$ & Deposition Time \\
\hline PRCL 1 & 1 & $0.55 \mu \mathrm{m}$ & N/A \\
\hline PRCL 2 & Fine sample & $15 \mathrm{~min}$ \\
& 1 & Rough sample & $15 \mathrm{~min}$ \\
& 2 & Fine sample & $30 \mathrm{~min}$ \\
& 3 & Rough sample & $30 \mathrm{~min}$ \\
& 4 & Fine sample & $45 \mathrm{~min}$ \\
& 5 & Rough sample & $45 \mathrm{~min}$ \\
\hline PRCL 3 & 6 & Fine sample & $15 \mathrm{~min}$ \\
& 1 & Rough sample & $15 \mathrm{~min}$ \\
& 2 & Fine sample & $30 \mathrm{~min}$ \\
& 3 & Rough sample & $30 \mathrm{~min}$ \\
& 4 & Fine sample & $45 \mathrm{~min}$ \\
& 5 & Rough sample & $45 \mathrm{~min}$ \\
\hline PRCL 4 & 6 & & \\
& & & \\
& 1 & &
\end{tabular}

adhesion tests were performed on a progressive load type testing machine CSM (model MSTX S/N: 01-2569). The testing machine employed Rockwell type diamond indenter with a nose radius of $100 \mu \mathrm{m}$. Applied load was starting from $0.03 \mathrm{~N}$, and the maximum final load was approximately 25 $\mathrm{N}$, with increasing loading rate of $9.99 \mathrm{~N} / \mathrm{min}$. The critical load, which is also considered as scratch adhesion of the TiN coating with the substrate, is that particular value of the load at which the coating is completely delaminated and the substrate is visible. An example of the scratch images of intermediate thick coating sample is shown in the Figure 1.

2.4. Nanohardness Test. Nanoindentation method is being widely used conventionally for measuring the hardness of the coatings $[18,19]$. In the current study, CSM nanohardness tester (model NHTX S/N: 01-2569) has been used for evaluating the coating hardness by nanoindentation method. The instrument employs a Berkovich type diamond indenter. Maximum load used in this testing was $40.0 \mathrm{mN}$ while loading and unloading rate was $80.0 \mathrm{mN} / \mathrm{min}$. The hardness of the TiN coatings of all samples with respect to the thickness and varying roughness of the substrate surfaces are presented in the later section.

2.5. Coating Thickness Measurement. Scanning Electron Microscope (TESCAN Vega LMU) was used to measure the TiN coating thickness on cylinder liner samples. The cylinder liner samples were prepared by wet grinding on the mechanical grinder. Emery papers (from 400-2500-micron grit) were used for the preparation of cross-sections of TiN coated cylinder liners. After this samples were kept in the 
TABLE 3: TiN coating Thicknesses of three batches corresponding to deposition times.

\begin{tabular}{lc}
\hline Deposition Time $(\mathrm{min})$ & Coating Thickness $(\mu \mathrm{m})$ \\
\hline 15 & $\approx 1.920$ \\
30 & $\approx 3.523$ \\
45 & $\approx 5.120$ \\
\hline
\end{tabular}

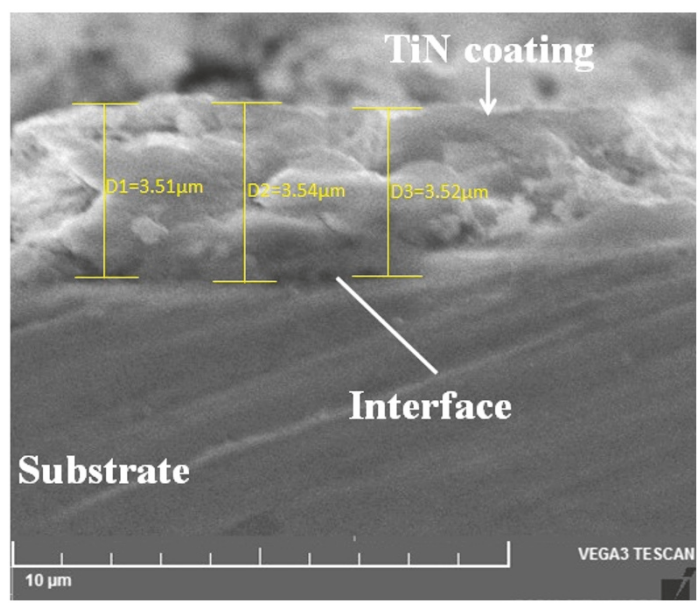

FIGURE 2: SEM image of cylinder liner sample at 30min deposition $(\approx 3.523 \mu \mathrm{m})$.

electric oven for moisture removing about 30 minutes at the temperature of $45^{\circ} \mathrm{C}$. The SEM image of TiN coating on cylinder liner deposited for $30 \mathrm{~min}$ is shown in Figure 2. The thickness was estimated at three different points and the average value was considered as the approximate thickness of the TiN coating. The summary of SEM measured approximate thickness values of the three batches with respect to deposition times is given in Table 3 .

2.6. Tribometer Tests. The coefficient of friction between the piston rings and the cylinder liner samples was evaluated using linear reciprocating tribometer of CSM (model S/N 0102566). The cylinder liner specimen cutouts were mounted on a fixed holder as a lower sample equipped with force transducer for the friction force measurement. The piston ring segments were inserted in an adjustable ring holder as an upper sample which was moved by the electric drive linearly reciprocated against the counter cylinder liner samples. A schematic diagram of the tribometer setup is shown in Figure 3.

A normal load was exerted to the piston ring holder and tests were conducted under lubricated conditions. SAE 15W40 lubrication oil recommended for this diesel engine was used as the lubricant. Properties of lubricant oil SAE 15W40 are given in Table 4. Prior to testing, both specimens were cleaned ultrasonically in alcohol. Tests were carried out at ambient temperature $\left(25^{\circ} \mathrm{C}\right)$ and stroke length was $6 \mathrm{~mm}$. The detailed test parameters are summarized in Table 5 .

The coefficient of friction was measured during the test and wear rate was calculated from the weight loss of cylinder
TABLE 4: Properties of lubricant oil grade SAE 15W-40.

\begin{tabular}{lc}
\hline Parameters & Values \\
\hline Kinematic viscosity @ & $15 \mathrm{~mm}^{2} / \mathrm{s}$ \\
$100^{\circ} \mathrm{C}$ & $106.9 \mathrm{~mm}^{2} / \mathrm{s}$ \\
Kinematic viscosity @ $40^{\circ} \mathrm{C}$ & 146 \\
Viscosity index & $-38^{\circ} \mathrm{C}$ \\
Pour point & $232^{\circ} \mathrm{C}$ \\
Flash point & $262^{\circ} \mathrm{C}$ \\
Fire point
\end{tabular}

TABLE 5: Tribometer operating parameters.

\begin{tabular}{lc}
\hline Parameters & Values \\
\hline Maximum Linear speed & $70.0 \mathrm{~mm} / \mathrm{s}$ \\
Normal load & $7.00 \mathrm{~N}$ \\
Number of Cycles & 6700 \\
Acquisition Rate & $10.0 \mathrm{~Hz}$ \\
Duration & $30 \mathrm{~min}$ \\
\hline
\end{tabular}

liner and piston rings specimens before and after the test [20]. After the tests, all the samples were kept in an ultrasonic bath for 15 minutes so that the accumulated wear debris were removed and yield the accurate weights of the specimens.

\section{Results and Discussion}

3.1. Effect of TiN Coating Thickness on Surface Roughness. Figures 4(a) and 4(b) show the surface roughness of the fine and rough type cylinder liner sample respectively before and after the deposition as the function of TiN coating thickness. The roughness of the sample surface reduces as the TiN coating grows thicker. The percentage improvement in the roughness of TiN coatings as compared to the starting roughness of the cylinder liners increases with increasing coating thickness irrespective of the starting roughness of the samples for both fine and rough samples. A summary of surface roughness values of cylinder liner samples before and after the deposition is shown in Table 6. The impact of asperities or uneven surface of the bare substrate gradually minimizes as the coating thickness gets larger.

3.2. Effect of Coating Thickness and Surface Roughness on Hardness. Figure 5 explains the effect of increasing TiN coating thickness on its hardness with respect to the two different levels of the roughness of the grey cast iron cylinder liners. Hardness appears to be strongly dependent on the thickness of the coating. It becomes greater as the coating thickness increases for both fine and rough samples. However, rough samples exhibit more hardness of the TiN coating deposited on them than the fine samples. Initially, the difference between the hardness values of fine and rough samples is large but it tends to decline as coating thickness increases. A nearly 5 um thick low-temperature PVD deposited TiN coating tends to achieve a hardness of $10-11 \mathrm{GPa}$ irrespective 


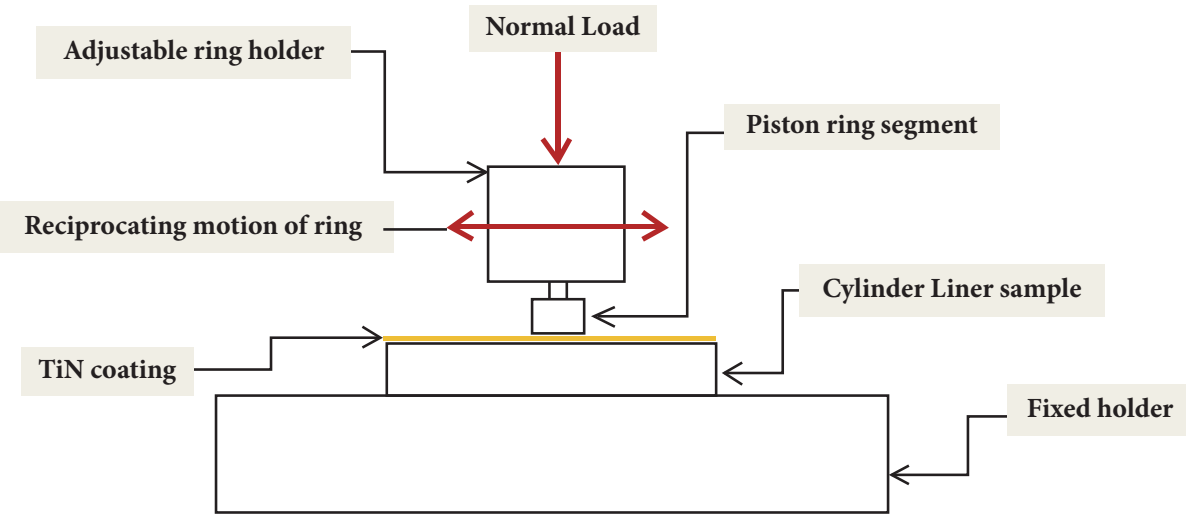

FIGURE 3: Schematic diagram of cylinder liner and piston ring contact.

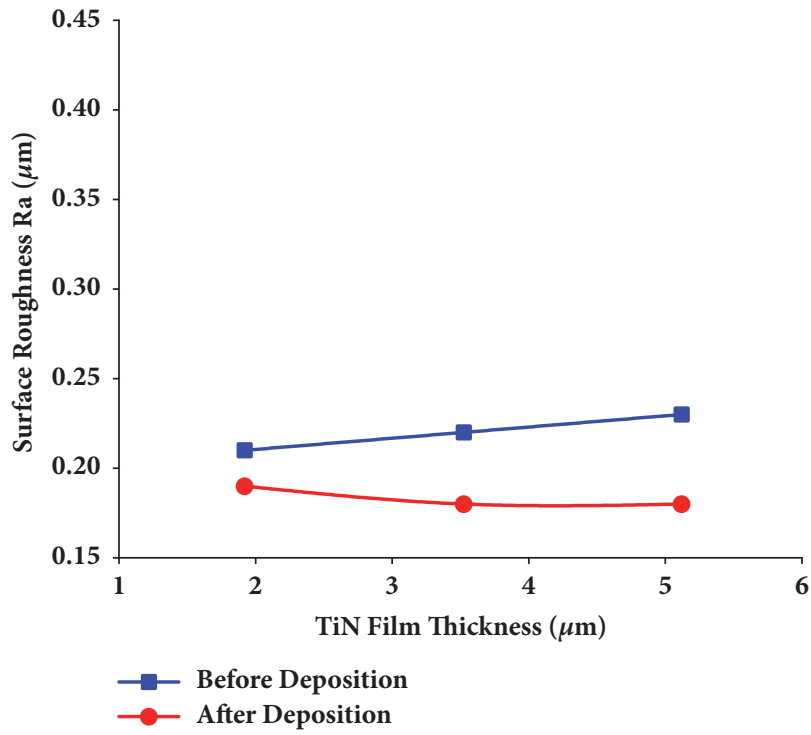

(a)

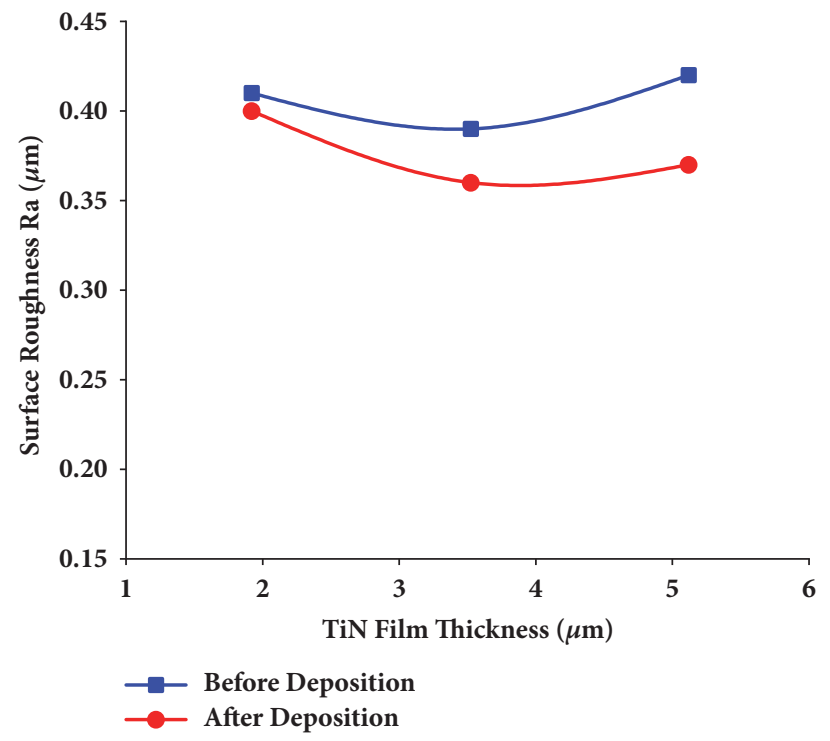

(b)

FIGURE 4: Surface roughness of cylinder liner samples before and after deposition as a function of TiN coating thickness: (a) fine samples; (b) rough samples.

TABLE 6: Surface roughness of cylinder liner samples before and after coating.

\begin{tabular}{|c|c|c|c|c|}
\hline $\begin{array}{l}\text { Coating } \\
\text { Thickness } \\
(\mu \mathrm{m})\end{array}$ & $\begin{array}{c}\text { Fine Samples } \\
\text { Surface Roughness } \\
\text { Before Coating } \\
\operatorname{Ra}(\mu \mathrm{m}) \\
\end{array}$ & $\begin{array}{c}\text { Fine Samples } \\
\text { Surface Roughness } \\
\text { After Coating } \\
\operatorname{Ra}(\mu \mathrm{m})\end{array}$ & $\begin{array}{c}\text { Rough Samples } \\
\text { Surface Roughness } \\
\text { Before Coating } \\
\operatorname{Ra}(\mu \mathrm{m}) \\
\end{array}$ & $\begin{array}{c}\text { Rough Samples } \\
\text { Surface Roughness } \\
\text { After Coating } \\
\operatorname{Ra}(\mu \mathrm{m})\end{array}$ \\
\hline$\approx 1.920$ & 0.21 & 0.19 & 0.41 & 0.40 \\
\hline$\approx 3.523$ & 0.22 & 0.18 & 0.39 & 0.36 \\
\hline$\approx 5.120$ & 0.23 & 0.18 & 0.42 & 0.37 \\
\hline
\end{tabular}

of the roughness of the grey cast iron substrate. Results of the hardness of TiN coating of cylinder liners are given in Table 7.

\subsection{Effect of Coating Thickness and Surface Roughness on} Adhesion. Figure 6 shows the variation in the scratch adhesion of TiN coatings on grey cast iron cylinder liner samples with respect to coating thickness and surface roughness.
Rough samples show a superior adhesion of TiN coatings as compared to fine samples. This phenomenon indicates that the adhesion of the coating is a function of interlocking of TiN coating with the asperities on the surface of grey cast iron cylinder liners and not the chemical bonding at the interface. On average, there is approximately $20 \%$ superior scratch adhesion of the TiN coatings on the rough grey cast iron cylinder liners as compared to the fine ones. Results of 
TABLE 7: Results of hardness and scratch adhesion of TiN coating of cylinder liners.

\begin{tabular}{lcccc}
\hline $\begin{array}{l}\text { Coating Thickness } \\
(\mu \mathrm{m})\end{array}$ & $\begin{array}{c}\text { Fine Samples } \\
\text { Hardness }(\mathrm{GPa})\end{array}$ & $\begin{array}{c}\text { Rough Samples } \\
\text { Hardness }(\mathrm{GPa})\end{array}$ & $\begin{array}{c}\text { Fine Samples } \\
\text { Adhesion }(\mathrm{N})\end{array}$ & $\begin{array}{c}\text { Rough Samples } \\
\text { Adhesion }(\mathrm{N})\end{array}$ \\
\hline$\approx 1.920$ & 5.963 & 7.882 & 11.04 & 14.38 \\
$\approx 3.523$ & 7.587 & 9.477 & 11.60 & 14.07 \\
$\approx 5.120$ & 10.001 & 10.482 & 11.72 & 14.58 \\
\hline
\end{tabular}

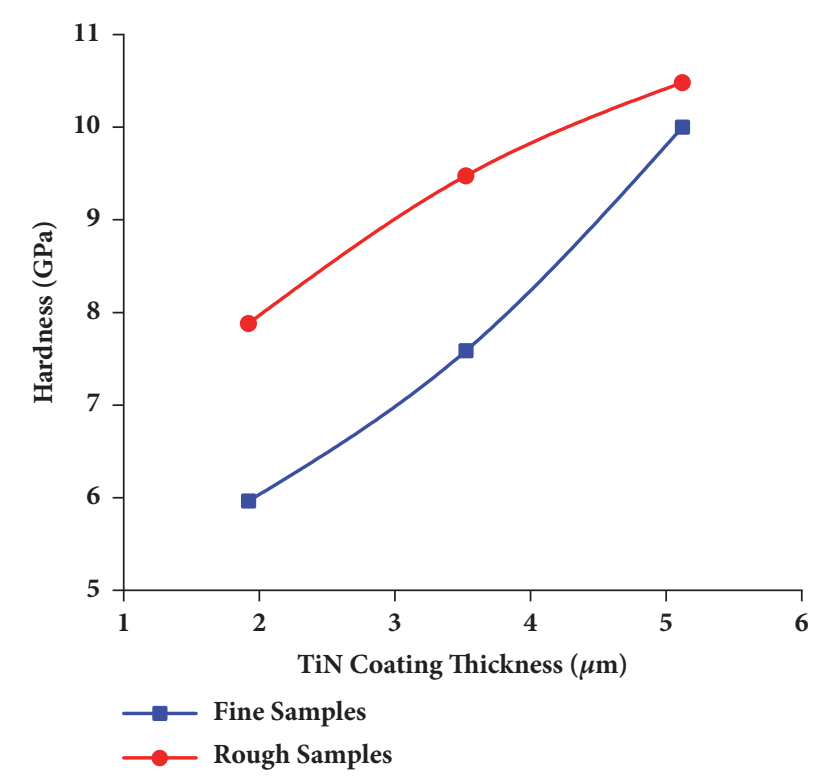

FIGURE 5: Effect of coating thickness and surface roughness on hardness.

scratch adhesion of TiN coating of cylinder liners are given in Table 7.

3.4. The Coefficient of Friction (COF) with respect to Coating Thickness and Surface Roughness. Figure 7 presents the plots of the coefficients of friction versus time for all four types of PRCL interface systems investigated in this study. Figure 7(a) summarizes the variations in COF trends between TiN coated and uncoated cylinder liners against TiN coated rings with respect to varying roughness of the cylinder liners and thickness of TiN coatings on them. For the thinnest TiN coated cylinder liner samples (thickness $\approx 1.920 \mu \mathrm{m}$ ), the COF gradually moves up for initial 10 minutes' span but after that the curves depict relatively greater rise in COF for both fine and rough samples. Intermediate thick $(\approx 3.523 \mu \mathrm{m})$ samples also show a slight gradual increase up to $10 \mathrm{~min}$ but after that the curves remained in a stable trend. Similarly, in thick coated $(\approx 5.120 \mu \mathrm{m})$ fine sample; COF almost remains constant after the initial slight increase at the start. But, the rough sample shows slight rise followed by a large decline for few seconds, then it becomes stable after the gradual increase. Moreover, TiN coated fine cylinder liner samples generally have a relatively lower COF than rough samples at the PRCL interface.

Figure 7(b) summarizes the variations in COF trends TiN coated and uncoated cylinder liners against chromium coated rings with respect to varying roughness of the liners and thickness of $\mathrm{TiN}$ coatings on them. It further compares the $\mathrm{COF}$ performances of these interfaces with the performance of the as is scenario, i.e., the bare grey cast iron cylinder liner with a surface roughness of $0.55 \pm 0.05 \mu \mathrm{m}$ against the chromium coated ring. Opposite behaviour in this case was observed. The TiN coated rough samples show relatively less COF against chromium coated rings than TiN coated fine samples do against chromium coated rings. This can be explained by the higher hardness of TiN coatings being more comparable with the hardness of chromium coated rings. COF gradually rise up throughout the experiment for the thinnest TiN coated samples irrespective of the roughness of the corresponding cylinder liners. The behaviour is almost the same for the intermediate TiN coating thickness samples but the fine samples show more increases and mean values of COF. The COF of the thickest TiN coated fine sample remains constant throughout the experiment suggesting a negligible effect of chromium of the ring on the very low roughness surface of the very hard TiN thick coating. However, for the thickest TiN coated rough cylinder liner sample versus the chromium coated rings the COF becomes stable after several rises and fall up to $12 \mathrm{~min}$. This suggests the wearing effect of the hardest and rough surface of $\mathrm{TiN}$ coatings on the relatively low hardness chromium rings.

The as is scenario, i.e., uncoated liner against the chromium coated ring, exhibits constant nonlinear increase in the COF. This is fundamentally due to high hardness chromium coated rings $(5.4 \mathrm{GPa})$ [21] wearing off the relatively low hardness grey cast iron cylinder liner. However, the sample with uncoated liner against TiN coated ring exhibits the gradual continuous increase but larger mean COF in comparison with as is scenario (see Figure 7(a)).

Figure 8 shows the variation in mean COF values with the change in TiN coating thickness on the cylinder liners and their varying roughness; the error bar shows one standard deviation. Figure 8(a) summarizes the trend of mean COF values for TiN coated cylinder liners against TiN coated rings compared against the mean COF value of as is scenario. Figure 8 (b) summarizes the trend of mean COF values for TiN coated cylinder liners against chromium coated rings compared against the mean COF value of the as is scenario. COF decreases with increasing the coating thickness for both fine and rough samples in case of TiN coated cylinder liner against TiN coated rings (see Figure 8(a)). However, fine samples show relatively lower COF as compared to rough samples. Therefore, there is a trade-off between the roughness of the TiN coated cylinder liner and the hardness of the corresponding TiN coating. Moreover, the minimum COF was observed for the thickest of the $\mathrm{TiN}$ film $(\approx 5.120 \mu \mathrm{m})$ samples against TiN coated rings when compared with the 


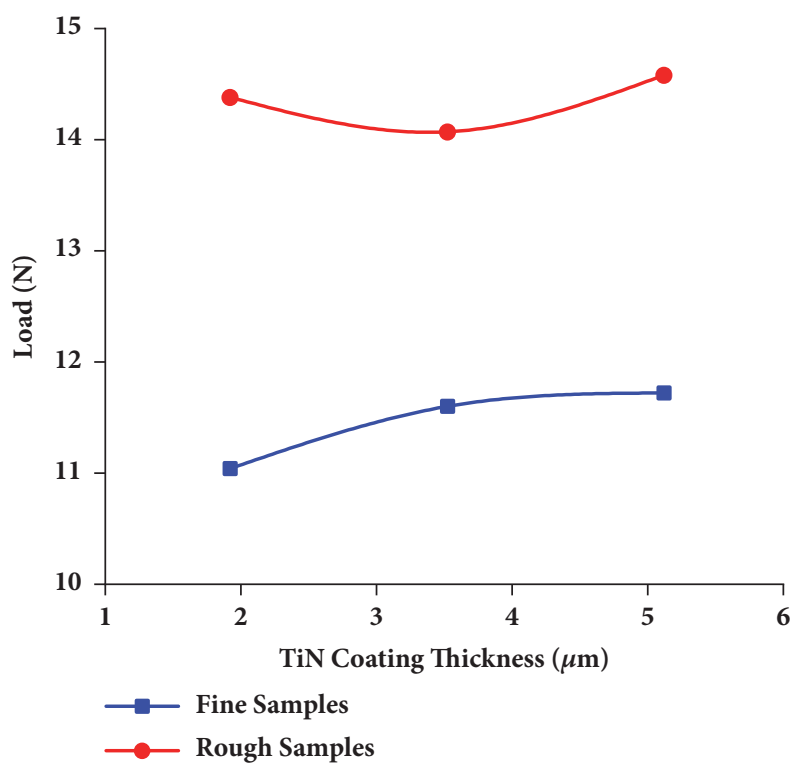

FIGURE 6: Effect of coating thickness and surface roughness on adhesion.

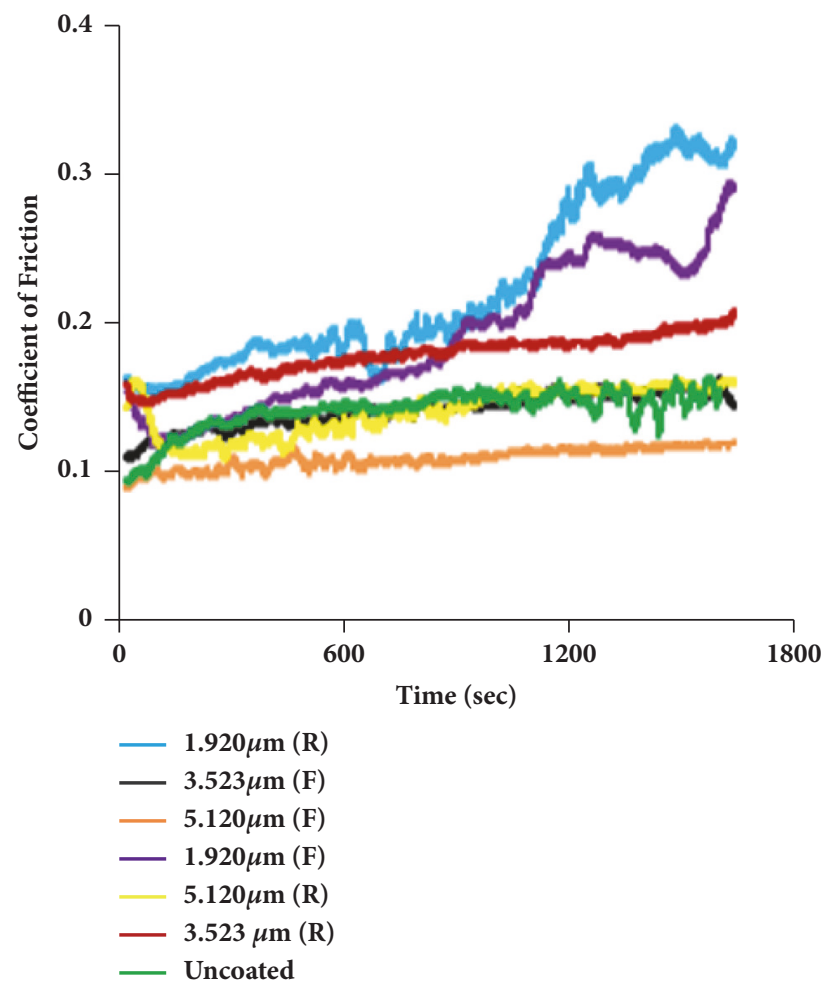

(a)

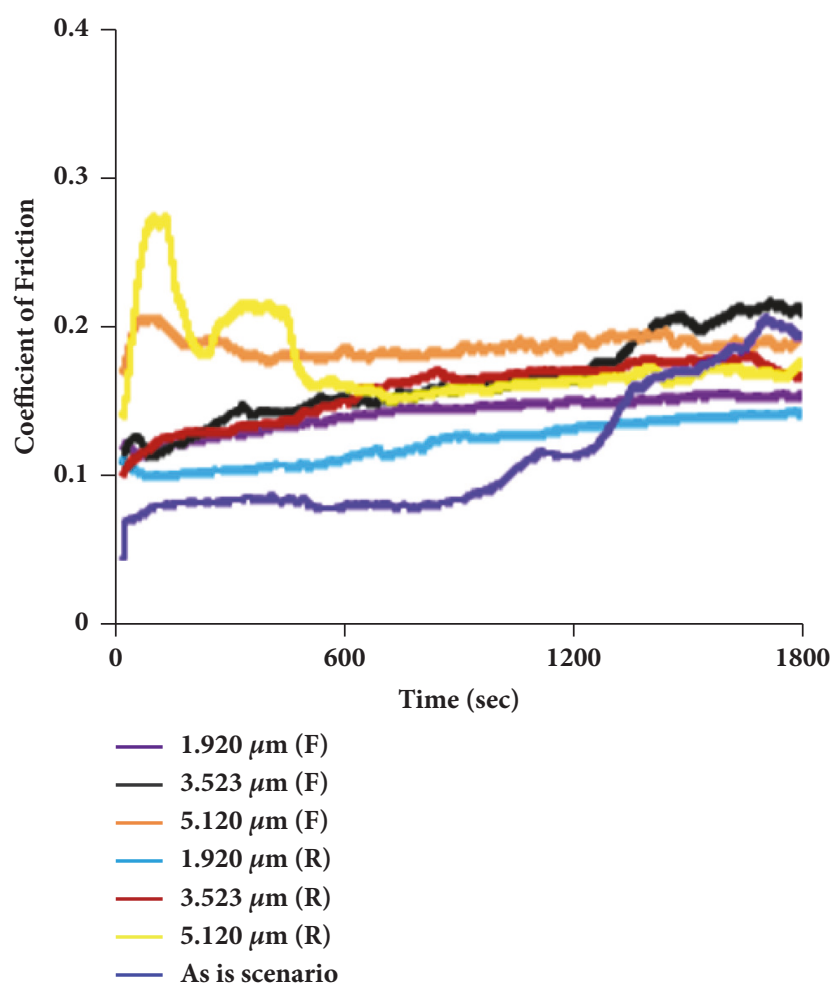

(b)

Figure 7: Graphs showing coefficient of friction as a function of time for (a) TiN coated and uncoated cylinder liners against TiN coated rings; (b) TiN coated and uncoated cylinder liners against $\mathrm{Cr}$ coated rings.

$\mathrm{COF}$ of the as is scenario. On the other hand, COF increases with increasing coating thickness for both fine and rough samples, when used the TiN coated cylinder liners against the chromium coated rings (see Figure $8(\mathrm{~b})$ ). The rough samples generally show lower COF than fine samples and the minimum COF was obtained at thinnest TiN coated $(\approx 1.920 \mu \mathrm{m})$ samples when compared with mean COF of as is scenario. 


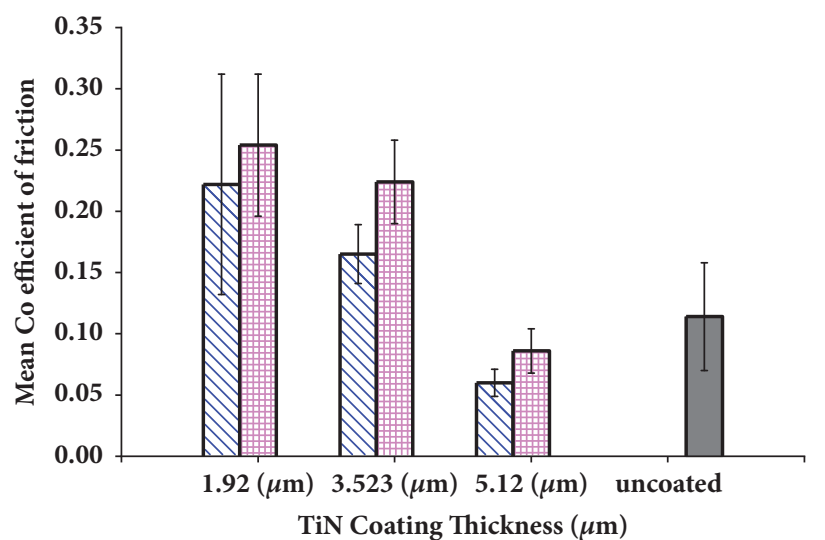

TiN Coating Thickness $(\mu \mathrm{m})$

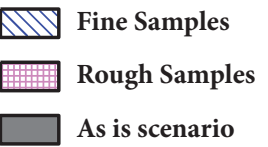

(a)
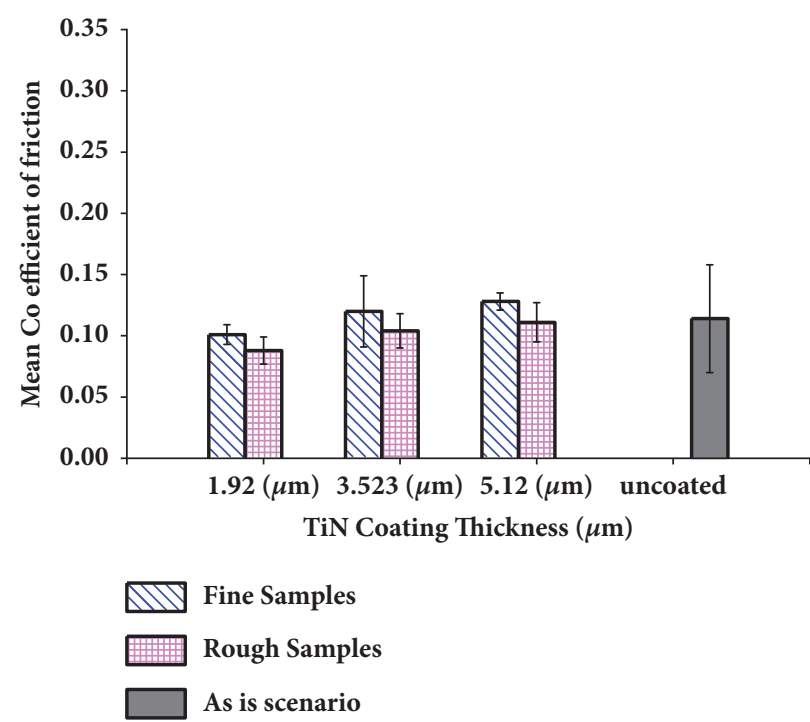

(b)

FIgURE 8: Variation in mean COF with TiN coating thickness: (a) both cylinder liner and rings are TiN coated (PRCL 2); (b) TiN coated cylinder liner with $\mathrm{Cr}$ coated rings (PRCL 3). The error bars represent the standard deviation of the experiment.

TABLE 8: Results of $\mathrm{H} / \mathrm{E}$ and $\mathrm{H}^{3} / \mathrm{E}^{2}$ ratio.

\begin{tabular}{lcccccccc}
\hline $\begin{array}{l}\text { Coating } \\
\text { Thickness } \\
(\mu \mathrm{m})\end{array}$ & $\begin{array}{c}\text { H Fine } \\
\text { Samples } \\
(\mathrm{GPa})\end{array}$ & $\begin{array}{c}\text { H Rough } \\
\text { Samples } \\
(\mathrm{GPa})\end{array}$ & $\begin{array}{c}\text { E Fine } \\
\text { Samples } \\
(\mathrm{GPa})\end{array}$ & $\begin{array}{c}\text { E Rough } \\
\text { Samples } \\
(\mathrm{GPa})\end{array}$ & $\begin{array}{c}\text { H/E Fine } \\
\text { Samples }\end{array}$ & $\begin{array}{c}\mathrm{H} / \mathrm{E} \\
\text { Rough } \\
\text { Samples }\end{array}$ & $\begin{array}{c}\mathrm{H}^{3} / \mathrm{E}^{2} \text { Fine } \\
\text { Samples } \\
(\mathrm{GPa})\end{array}$ & $\begin{array}{c}\mathrm{H}^{3} / \mathrm{E}^{2} \text { Rough } \\
\text { Samples } \\
(\mathrm{GPa})\end{array}$ \\
\hline$\approx 1.920$ & 5.963 & 7.882 & 184.707 & 184.741 & 0.03228 & 0.042665 & 0.006215 \\
$\approx 3.523$ & 7.587 & 9.477 & 190.327 & 206.857 & 0.03986 & 0.045814 & 0.012056 & 0.014348 \\
$\approx 5.120$ & 10.001 & 10.482 & 215.275 & 226.434 & 0.04646 & 0.046292 & 0.021585 & 0.022462 \\
\hline
\end{tabular}

3.5. Wear Rate with respect to Coating Thickness and Surface Roughness. Traditionally, it is considered that wear resistance of the coatings just depends on the hardness but nevertheless, elastic modulus also plays a vital contribution in the wear characteristics. The ratio $\mathrm{H} / \mathrm{E}$ (elastic to strain failure) is one of the parameters for predicting the wear of the hard coatings. However, $\mathrm{H}^{3} / \mathrm{E}^{2}$ ratio (resistance to plastic deformation) is cited as a preferable parameter for assessing the wear resistance of the hard coatings [22,23]. Detailed results of $\mathrm{H} / \mathrm{E}$ and $\mathrm{H}^{3} / \mathrm{E}^{2}$ ratio are presented in Table 8 .

Figure 9 shows the variation in wear rate of cylinder liners and piston rings with the change in TiN coating thickness on the cylinder liners and their varying roughness; the error bar marks one standard deviation. Figure 9(a) shows the trend of wear rate for TiN coated cylinder liners against TiN coated rings compared against the wear rate value of as is scenario. Figure 9(b) shows the trend of wear rate for TiN coated cylinder liners against chromium coated rings compared against the wear rate value of the as is scenario.

Wear rate of TiN coated cylinder liners against the TiN coated rings decreases as the coating thickness increases for both fine and rough samples. However, rough samples wear out less as compared to fine samples due to the higher $\mathrm{H}^{3} / \mathrm{E}^{2}$ ratio (as shown in Table 8). The increase in wear rate of fine samples is related to the drop in $\mathrm{H}^{3} / \mathrm{E}^{2}$ ratio and adhesion of the coating (as shown in Figure 9(a)). Good wear resistance of the TiN coated cylinder liners was observed when compared with the as is scenario and thickest $(\approx 5.120 \mu \mathrm{m})$ TiN coated cylinder liner samples exhibited lowest wear rate. But, wear rate of uncoated grey cast iron cylinder liner with TiN coated rings is more than as is scenario case.

On the other hand, TiN coated cylinder liners sliding against the $\mathrm{Cr}$ coated rings shows excellent wear resistance among all other three PRCL interfaces (in Figure 9(b)). The negative values of the wear rate suggest that the weight of the liners increases after the test. The $\mathrm{Cr}$ coated rings have relatively less hardness than the TiN coated cylinder liners (as in Table 7). Consequently, the Cr wears off and settles in the asperities of the TiN coated liner surface. Furthermore, the rough samples asperities accommodate more $\mathrm{Cr}$ debris on their surface as compared to fine samples as evident from Figure 9(b).

Figure 9(c) shows the trend of wear rate for TiN coated rings against TiN coated cylinder liners while Figure 9(d) shows the trend of wear rate for $\mathrm{Cr}$ coated rings against $\mathrm{TiN}$ coated cylinder liners. Ring wear rate shows opposite trend than the liner wear rate. Cr coated rings sliding against the fine samples of cylinder liners wear out less in comparison with rough samples for both the cases, i.e., TiN and Cr coated rings (as in Figures 9(c) and 9(d)). Ring wear rate increases 


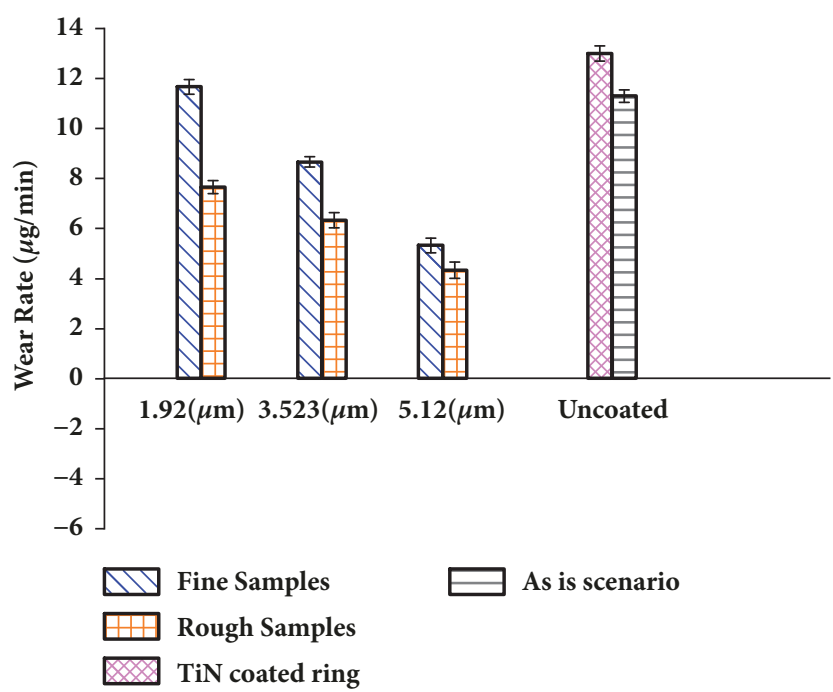

(a)

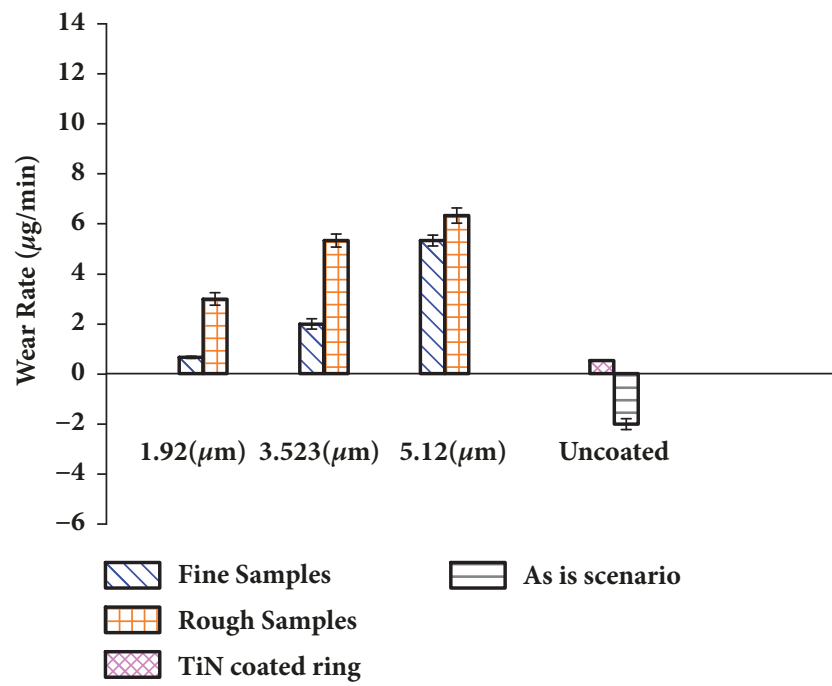

(c)

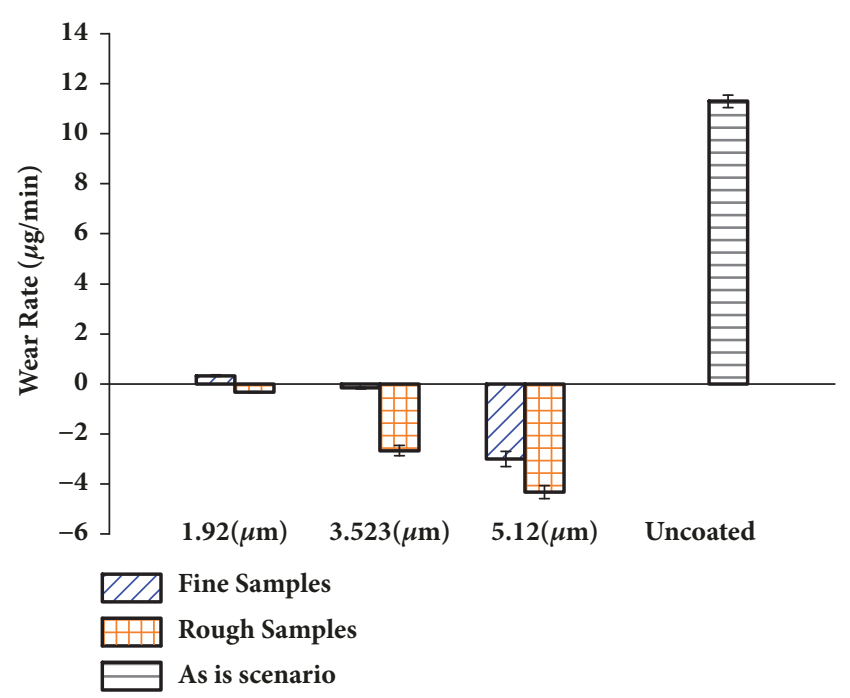

(b)

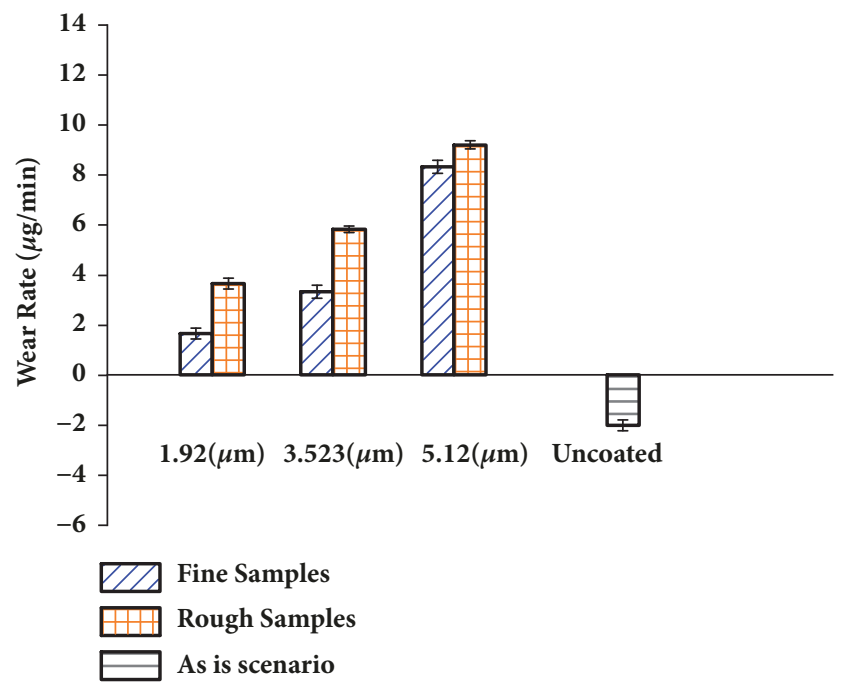

(d)

Figure 9: Wear rate as a function of TiN coating thickness: (a) cylinder liner wear rate when rings are TiN coated; (b) cylinder liner wear rate when rings are $\mathrm{Cr}$ coated; (c) wear rate of TiN coated piston rings; (d) wear rate of $\mathrm{Cr}$ coated piston rings. The error bars represent the standard deviation of the experiment.

with the increase in TiN coating thickness on the cylinder liners. But, the TiN coated rings exhibit relatively better wear resistance than $\mathrm{Cr}$ coated rings (as in Figures 9(c) and 9(d)). In as is scenario case, the wear rate of $\mathrm{Cr}$ coated rings shows negative value due to the increase in weight after adhesion of grey cast iron debris on their surface asperities during the test. This can be explained by the fact that grey cast iron cylinder liner has the hardness (2 GPa) [24] which is much lesser as compared to TiN coated cylinder liners (shown in Table 7) which result in more wear of the uncoated cylinder liners and less wear of the rings against them. However, TiN coated ring shows negligible wear resistance against uncoated cylinder liners. The detailed results of mean COF and wear rate are summarized in Table 9.
It can be concluded that the wear of the cylinder liners is dependent on the $\mathrm{H}^{3} / \mathrm{E}^{2}$ ratio of the TiN coatings and the hardness of the uncoated grey cast iron only. The rough samples give good wear resistance of the TiN coated cylinder liners against both $\mathrm{TiN}$ coated and $\mathrm{Cr}$ coated rings (as shown in Figure 9) due to higher $\mathrm{H}^{3} / \mathrm{E}^{2}$ ratio. In contrast, $\mathrm{COF}$ depends on not only hardness but also the surface roughness too, as the fine samples give less COF but more wear rate in comparison with the rough samples in case of TiN coated rings (as shown in Figure 8). COF in the case of $\mathrm{Cr}$ coated rings show different trend; i.e., rough samples give less $\mathrm{COF}$ than fine samples and COF is the minimum where the $\mathrm{H}^{3} / \mathrm{E}^{2}$ ratio of cylinder liner samples is relatively lower. Wear of the rings is directly related to $\mathrm{H}^{3} / \mathrm{E}^{2}$ ratio and roughness of the 
TABLE 9: Summary of mean COF and wear rate results.

\begin{tabular}{|c|c|c|c|c|c|c|}
\hline PRCL system & Sample ID & $\begin{array}{c}\text { Surface } \\
\text { Roughness }\end{array}$ & $\begin{array}{l}\text { Coating } \\
\text { Thickness }\end{array}$ & Mean COF & $\begin{array}{c}\text { Cylinder Liner } \\
\text { Wear Rate } \\
(\mu \mathrm{g} / \mathrm{min})\end{array}$ & $\begin{array}{c}\text { Piston Ring } \\
\text { Wear Rate } \\
(\mu \mathrm{g} / \mathrm{min}) \\
\end{array}$ \\
\hline \multirow[t]{2}{*}{ PRCL 1 (As is scenario) } & \multicolumn{6}{|c|}{ Uncoated Cylinder Liner against Cr Coated Piston Ring } \\
\hline & 1 & $0.55 \mu \mathrm{m}$ & N/A & 0.114 & 11.30 & -2.0 \\
\hline \multirow[t]{7}{*}{ PRCL 2} & \multicolumn{6}{|c|}{ TiN Coated Cylinder Liner against TiN Coated Piston Rings } \\
\hline & 1 & Fine sample & $\approx 1.920 \mu \mathrm{m}$ & 0.222 & 11.67 & 0.67 \\
\hline & 2 & Rough sample & $\approx 1.920 \mu \mathrm{m}$ & 0.254 & 7.67 & 3 \\
\hline & 3 & Fine sample & $\approx 3.523 \mu \mathrm{m}$ & 0.165 & 8.67 & 2 \\
\hline & 4 & Rough sample & $\approx 3.523 \mu \mathrm{m}$ & 0.224 & 6.33 & 5.33 \\
\hline & 5 & Fine sample & $\approx 5.120 \mu \mathrm{m}$ & 0.06 & 5.33 & 5.33 \\
\hline & 6 & Rough sample & $\approx 5.120 \mu \mathrm{m}$ & 0.086 & 4.33 & 6.33 \\
\hline \multirow[t]{7}{*}{ PRCL 3} & \multicolumn{6}{|c|}{ TiN Coated Cylinder Liner against Cr Coated Piston Rings } \\
\hline & 1 & Fine sample & $\approx 1.920 \mu \mathrm{m}$ & 0.101 & 0.33 & 1.67 \\
\hline & 2 & Rough sample & $\approx 1.920 \mu \mathrm{m}$ & 0.088 & -0.33 & 3.67 \\
\hline & 3 & Fine sample & $\approx 3.523 \mu \mathrm{m}$ & 0.12 & -0.16 & 3.33 \\
\hline & 4 & Rough sample & $\approx 3.523 \mu \mathrm{m}$ & 0.104 & -2.67 & 5.83 \\
\hline & 5 & Fine sample & $\approx 5.120 \mu \mathrm{m}$ & 0.128 & -3 & 8.33 \\
\hline & 6 & Rough sample & $\approx 5.120 \mu \mathrm{m}$ & 0.111 & -4.33 & 9.21 \\
\hline \multirow[t]{2}{*}{ PRCL 4} & \multicolumn{6}{|c|}{ Uncoated Cylinder Liner against TiN Coated Piston Ring } \\
\hline & 1 & $0.55 \mu \mathrm{m}$ & N/A & 0.157 & 13 & 0.54 \\
\hline
\end{tabular}

TiN coated cylinder liners. Wear of the rings is the minimum when they slide against thinnest TiN coated fine cylinder liners (for both TiN and Cr coated rings) as $\mathrm{H}^{3} / \mathrm{E}^{2}$ ratio is relatively lower among all samples. So, there are multiple trade-offs between the wear and COF based on hardness and roughness. A summary of tribological trade-off is presented in Table 10.

\section{Conclusions and Recommendation}

The purpose of this experimental study is to compare the mechanical and tribological properties of an existing diesel engine PRCL system with different combinations of lowtemperature TiN PVD coated interfacing surfaces of same PRCL system. The following conclusions are drawn from this study:

Surface roughness improves with the increase in TiN coating on the cylinder liners for both fine and rough samples. However, the impact of surface roughness improvement is seen more on rough samples. Hardness and adhesion are dependent on the surface roughness and coating thickness. Hardness and adhesion increase with the increase in TiN coating thickness but rough samples show these micromechanical properties superior to the fine samples.

Wear is primarily a hardness dependent phenomenon but COF depends on both surface roughness and hardness. Cylinder liner samples having higher $\mathrm{H}^{3} / \mathrm{E}^{2}$ ratio show less wear rate and consequently more wear rate of the piston rings sliding against them. However, COF presents different trend for TiN coated cylinder liners against $\mathrm{TiN}$ and $\mathrm{Cr}$ coated rings with respect to hardness and surface roughness. All the samples of PRCL 2 show decrease in mean COF with the increase in coating thickness. However, fine samples have inferior COF than rough samples. In contrast, mean COF of all the samples of PRCL 3 increases with the increase in coating thickness and rough samples have higher COF than fine samples.

Reduction in COF may not necessarily give optimum results of wear of TiN coated cylinder liners and rings. Cylinder liners and piston rings do not show same wear resistance at the same time. More reduction in coefficient of friction amounts to more fuel saving. On the other hand, more reliability of the PRCL system is achieved by making cylinder liner more wear resistant keeping piston ring as a sacrificial component and hence reducing the maintenance cost and increasing the life of the engine.

Finally, we have quantitatively reported multiple tradeoffs of COF and wear rate of cylinder liners for the designers to select the optimum PRCL system. Sample 5 of PRCL 2 interface gives $47 \%$ reduction in mean COF and 53\% reduction in cylinder liner wear rate. Sample 6 of PRCL 2 interface gives $24 \%$ reduction in mean COF and $62 \%$ reduction in cylinder liner wear. Sample 1 of PRCL 3 interface gives $11 \%$ reduction in mean $\mathrm{COF}$ and $97 \%$ reduction in cylinder liner wear rate. Sample 2 of PRCL 3 interface gives $23 \%$ reduction in mean COF with excellent wear resistance.

It is recommended to investigate the impact of these savings in COF and wear rate on the specific fuel consumption, maintenance cost, and reliability on a full-scale engine test rig. 
TABLE 10: Summary of tribological results trade-offs, the percentage changes in mean COF, and cylinder liner wear rate are calculated in comparison to the PRCL 1 (as is scenario).

\begin{tabular}{|c|c|c|c|c|c|}
\hline PRCL system & Sample ID & $\begin{array}{c}\text { Surface } \\
\text { Roughness }\end{array}$ & $\begin{array}{l}\text { Coating } \\
\text { Thickness }\end{array}$ & $\begin{array}{c}\text { Comparison } \\
\text { with mean COF } \\
\text { of PRCL } 1\end{array}$ & $\begin{array}{c}\text { Comparison } \\
\text { with cylinder } \\
\text { liner wear rate } \\
\text { of PRCL } 1\end{array}$ \\
\hline \multirow[t]{2}{*}{ PRCL 1} & \multicolumn{4}{|c|}{ Uncoated Cylinder Liner against Cr Coated Piston Ring } & \\
\hline & 1 & $0.55 \mu \mathrm{m}$ & $\mathrm{N} / \mathrm{A}$ & $\mathrm{N} / \mathrm{A}$ & N/A \\
\hline \multirow[t]{7}{*}{ PRCL 2} & \multicolumn{4}{|c|}{ TiN Coated Cylinder Liner against TiN Coated Piston Rings } & \\
\hline & 1 & Fine sample & $\approx 1.920 \mu \mathrm{m}$ & $95 \%$ & $3 \%$ \\
\hline & 2 & Rough sample & $\approx 1.920 \mu \mathrm{m}$ & $122 \%$ & $-32 \%$ \\
\hline & 3 & Fine sample & $\approx 3.523 \mu \mathrm{m}$ & $45 \%$ & $-23 \%$ \\
\hline & 4 & Rough sample & $\approx 3.523 \mu \mathrm{m}$ & $96 \%$ & $-44 \%$ \\
\hline & 5 & Fine sample & $\approx 5.120 \mu \mathrm{m}$ & $-47 \%$ & $-53 \%$ \\
\hline & 6 & Rough sample & $\approx 5.120 \mu \mathrm{m}$ & $-24 \%$ & $-62 \%$ \\
\hline \multirow[t]{7}{*}{ PRCL 3} & \multicolumn{4}{|c|}{ TiN Coated Cylinder Liner against Cr Coated Piston Rings } & \multirow{7}{*}{$\begin{array}{l}\text { Negative wear } \\
\text { rate shows } \\
\text { excellent wear } \\
\text { resistance }\end{array}$} \\
\hline & 1 & Fine sample & $\approx 1.920 \mu \mathrm{m}$ & $-11 \%$ & \\
\hline & 2 & Rough sample & $\approx 1.920 \mu \mathrm{m}$ & $-23 \%$ & \\
\hline & 3 & Fine sample & $\approx 3.523 \mu \mathrm{m}$ & $5 \%$ & \\
\hline & 4 & Rough sample & $\approx 3.523 \mu \mathrm{m}$ & $-9 \%$ & \\
\hline & 5 & Fine sample & $\approx 5.120 \mu \mathrm{m}$ & $12 \%$ & \\
\hline & 6 & Rough sample & $\approx 5.120 \mu \mathrm{m}$ & $-2.60 \%$ & \\
\hline \multirow[t]{2}{*}{ PRCL 4} & \multicolumn{4}{|c|}{ Uncoated Cylinder Liner against TiN Coated Piston Ring } & \\
\hline & 1 & $0.55 \mu \mathrm{m}$ & $\mathrm{N} / \mathrm{A}$ & $37 \%$ & $15 \%$ \\
\hline
\end{tabular}

\section{Data Availability}

No data were used to support this study.

\section{Conflicts of Interest}

The authors declare that there are no conflicts of interest regarding the publication of this paper.

\section{Acknowledgments}

We would like to extend our sincere gratitude to Kleenex group and Millat Tractors Limited ${ }^{\circledR}$ for providing relevant technical support. We would like to thank Higher Education Commission (HEC), Pakistan, for the partial funding in order to carry out this research.

\section{References}

[1] G. Ryk, Y. Kligerman, I. Etsion, and A. Shinkarenko, "Experimental investigation of partial laser surface texturing for pistonring friction reduction," Tribology Transactions, vol. 48, no. 4, pp. 583-588, 2005.

[2] C. H. O. Dae-Hyun and L. E. E. Young-Ze, "Evaluation of ring surfaces with several coatings for friction, wear and scuffing life," Transactions of Nonferrous Metals Society of China, vol. 19, no. 4, pp. 992-996, 2009.

[3] S. Arumugam and G. Sriram, "Effect of Bio-Lubricant and Biodiesel-Contaminated Lubricant on Tribological Behavior of
Cylinder Liner-Piston Ring Combination," Tribology Transactions, vol. 55, no. 4, pp. 438-445, 2012.

[4] K. HolmberG and A. Matthews, Coatings tribology, Elsevier, Amsterdam, 1994.

[5] B. Bhushan and B. K. Gupta, Handbook of tribology, McGrawHill, New York, 1991.

[6] E. Santecchia, A. M. S. Hamouda, F. Musharavati, E. Zalnezhad, M. Cabibbo, and S. Spigarelli, "Wear resistance investigation of titanium nitride-based coatings," Ceramics International, vol. 41, no. 9, pp. 10349-10379, 2015.

[7] S. Paldey and S. C. Deevi, "Single layer and multilayer wear resistant coatings of $(\mathrm{Ti}, \mathrm{Al}) \mathrm{N}$ : A review," Materials Science and Engineering: A Structural Materials: Properties, Microstructure and Processing, vol. 342, no. 1-2, pp. 58-79, 2003.

[8] P. Hedenqvist, M. Bromark, M. Olsson, S. Hogmark, and E. Bergmann, "Mechanical and tribological characterization of low-temperature deposited PVD TiN coatings," Surface and Coatings Technology, vol. 63, no. 1-2, pp. 115-122, 1994.

[9] Š. Eperješi, J. Malik, I. Vasková, and D. Fecko, "Increasing of utility properties of grey cast iron castings with heat treatment," Archives of Foundry Engineering, vol. 15, no. 2, pp. 13-16, 2015.

[10] P. Pawlus, T. Cieslak, and T. Mathia, "The study of cylinder liner plateau honing process," Journal of Materials Processing Technology, vol. 209, no. 20, pp. 6078-6086, 2009.

[11] M. C. Malburg, J. Raja, and D. J. Whitehouse, "Characterization of Surface Texture Generated by Plateau Honing Process," CIRP Annals - Manufacturing Technology, vol. 42, no. 1, pp. 637-639, 1993.

[12] W. Grabon, P. Pawlus, S. Wos, W. Koszela, and M. Wieczorowski, "Effects of honed cylinder liner surface texture on 
tribological properties of piston ring-liner assembly in short time tests," Tribology International, vol. 113, pp. 137-148, 2017.

[13] A. Mubarak, P. Akhter, E. Hamzah, M. R. H. Mohd Toff, and I. A. Qazi, "Effect of coating thickness on the properties of TiN coatings deposited on tool steels using cathodic arc PVD technique," Surface Review and Letters, vol. 15, no. 4, pp. 401410, 2008.

[14] C. Öner, H. Hazar, and M. Nursoy, "Surface properties of CrN coated engine cylinders," Materials \& Design, vol. 30, no. 3, pp. 914-920, 2009.

[15] I. A. Polonsky, T. P. Chang, L. M. Keer, and W. D. Sproul, "A study of rolling-contact fatigue of bearing steel coated with physical vapor deposition TiN films: Coating response to cyclic contact stress and physical mechanisms underlying coating effect on the fatigue life," Wear, vol. 215, no. 1-2, pp. 191-204, 1998.

[16] W. Heinke, A. Leyland, A. Matthews, G. Berg, C. Friedrich, and E. Broszeit, "Evaluation of PVD nitride coatings, using impact, scratch and Rockwell-C adhesion tests," Thin Solid Films, vol. 270, no. 1-2, pp. 431-438, 1995.

[17] S. J. Bull and E. G. Berasetegui, "An overview of the potential of quantitative coating adhesion measurement by scratch testing," Tribology International, vol. 39, no. 2, pp. 99-114, 2006.

[18] X. Li and B. Bhushan, "A review of nanoindentation continuous stiffness measurement technique and its applications," Materials Characterization, vol. 48, no. 1, pp. 11-36, 2002.

[19] D. Beegan, S. Chowdhury, and M. T. Laugier, "Comparison between nanoindentation and scratch test hardness (scratch hardness) values of copper thin films on oxidised silicon substrates," Surface and Coatings Technology, vol. 201, no. 12, pp. 5804-5808, 2007.

[20] R. Ananthakumar, B. Subramanian, A. Kobayashi, and M. Jayachandran, "Electrochemical corrosion and materials properties of reactively sputtered TiN/TiAlN multilayer coatings," Ceramics International, vol. 38, no. 1, pp. 477-485, 2012.

[21] Y. Di, Z. Cai, and P. Zhang, "The tribological performance of CrMoN/MoS2 solid lubrication coating on a piston ring," Lubricants, vol. 5, no. 2, 13 pages, 2017.

[22] A. Leyland and A. Matthews, "On the significance of the H/E ratio in wear control: a nanocomposite coating approach to optimised tribological behaviour," Wear, vol. 246, no. 1-2, pp. $1-11,2000$.

[23] R. Trache, L. M. Berger, S. Saaro, and R. S. Lima, The Influence of Particle Temperature, Particle Velocity and Coating Surface Temperature on the Sliding Wear Performance of TiO2-Cr2O3 Coatings, ITSC, 2010.

[24] N. G. Demas, R. A. Erck, O. O. Ajayi, and G. R. Fenske, "Tribological studies of coated pistons sliding against cylinder liners under laboratory test conditions," Lubrication Science, vol. 24, no. 5, pp. 216-227, 2012. 


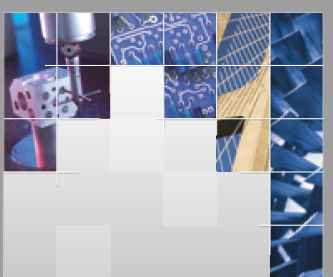

\section{Enfincering}
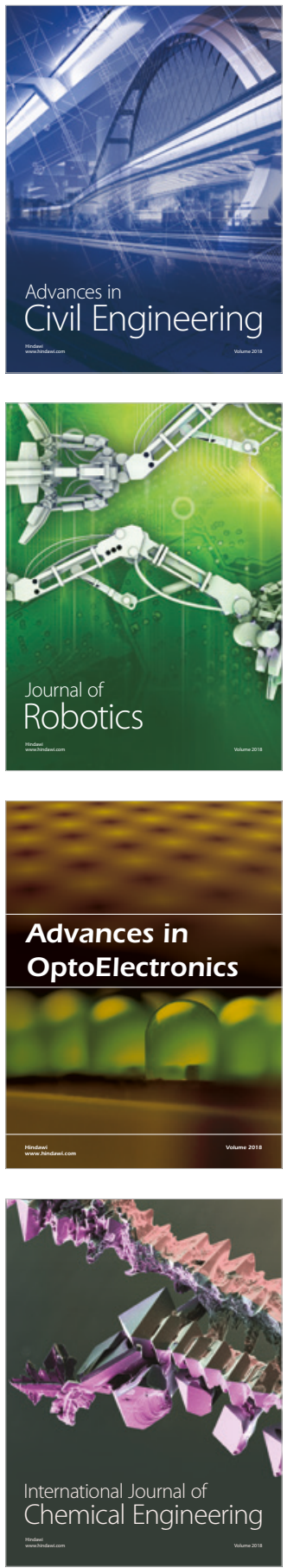

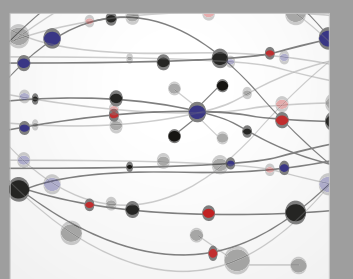

\section{Rotating \\ Machinery}

The Scientific World Journal

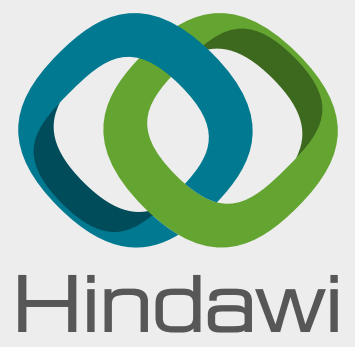

Submit your manuscripts at

www.hindawi.com
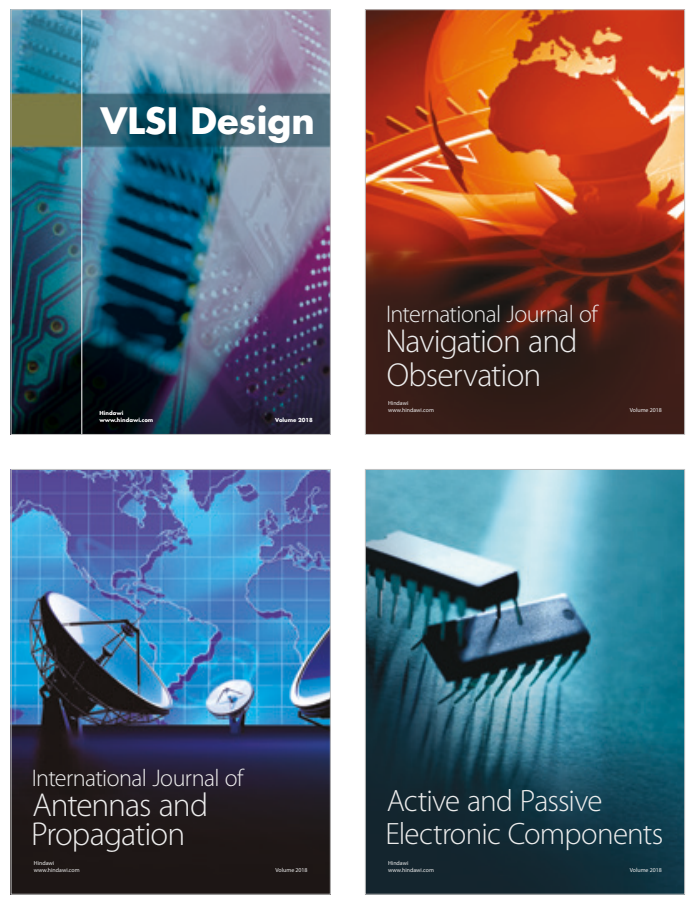
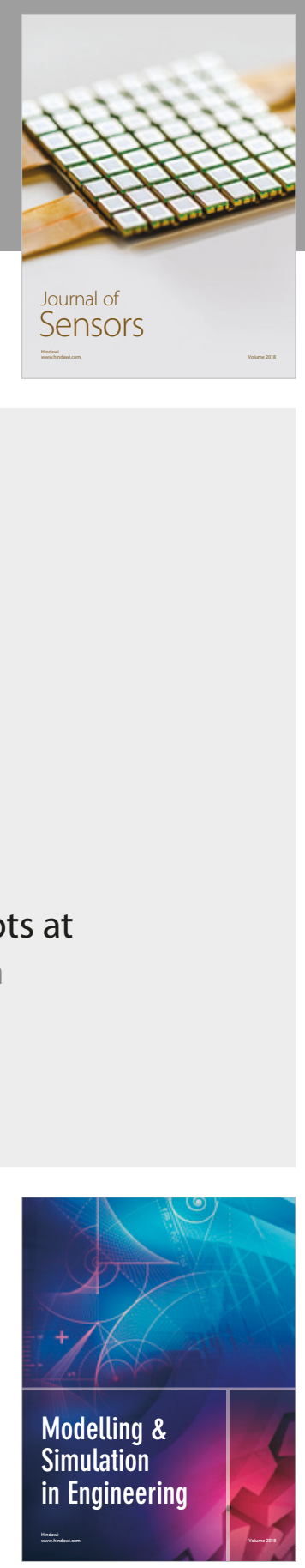

\section{Advances \\ Multimedia}
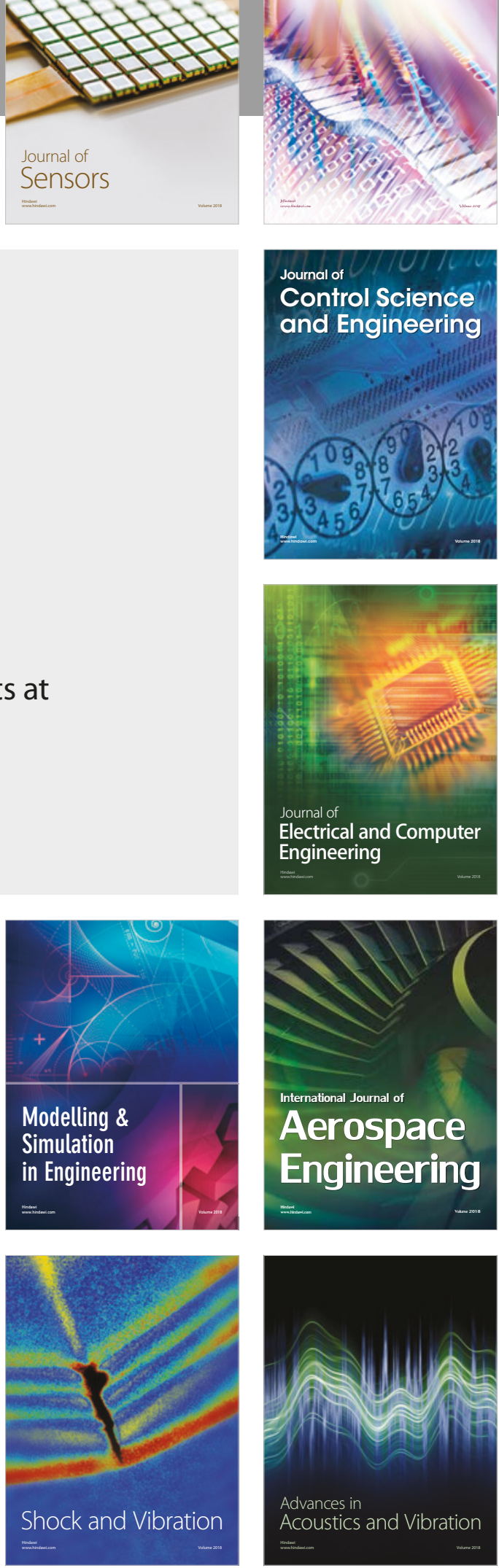